\title{
Women, pandemics and the Global South: an introductory overview
}

\author{
Bina Agarwal ${ }^{1} \cdot$ Ragupathy Venkatachalam $^{2} \cdot$ Floriana Cerniglia $^{3}$ \\ Published online: 3 March 2022 \\ (c) Springer Nature Switzerland AG 2022
}

\section{Special features}

Ever since the COVID-19 pandemic took over our lives and livelihoods, indeed even our imaginations, in early 2020, a notable body of work has emerged on its impact, including on women. In fact, several Journals have carried Special Issues on gender and the pandemic. ${ }^{1}$ Why then do we need yet another one? Indeed, what is special about this Special Issue of Economia Politica?

EPOL's Special Issue on Women, Pandemics and the Global South brings some unique features to our understanding of the COVID-19 effects which have not been covered by prior work. To begin with, our opening paper by Bina Agarwal provides a conceptual framework that traces the complexity of potential effects. This includes not only the direct effects but also the indirect ones, and not only the immediate effects but also those likely to emerge in the long term. Previous special issues of journals on gender and COVID focused overwhelmingly on women's unpaid care work, to the neglect of many other effects. ${ }^{2}$ Also, none of the other special issues were devoted to women in the Global South.

\footnotetext{
${ }^{1}$ For example, Feminist Economics (2021), Gender and Society (2021), and Feminist Studies (2020) all carried special issues on gender and COVID-19. In addition, articles on women and the pandemic were carried in other journal Special Issues not focused only on women, such as World Development.

2 As Agarwal notes in her paper in this Issue, this was the single most important focus of $60 \%$ of the articles in Feminist Economics (2021) and 56\% in Feminist Studies (2020).
}

Bina Agarwal

bina.agarwal@manchester.ac.uk

Ragupathy Venkatachalam

r.venkatachalam@gold.ac.uk

Floriana Cerniglia

floriana.cerniglia@unicatt.it

1 Global Development Institute, The University of Manchester, Manchester, UK

2 Institute of Management Studies, Goldsmiths, University of London, London, UK

3 Dipartimento di Economia Internazionale, delle istituzioni e dello sviluppo (DISEIS), Università Cattolica del Sacro Cuore, Milan, Italy 
Second, by applying the conceptual framework, we are also able to identify the data and information that are needed for a more comprehensive coverage of impact, as well as the gaps that persist. This is essential for a meaningful and effective policy response.

Third, we have the late-comer's advantage, in that several authors were able to draw upon panel data, especially on employment, which were not available for analysis earlier. These data help trace the employment effects by gender not only during the initial severe lockdowns but also under post-lockdown economic recoveries. In other words, we are able to analyse the results from a longer-term perspective than prior research.

Fourth, some authors included here were also able to undertake new field surveys, covering dimensions which none had covered so far, such as gender inequalities in food and nutritional intakes when families faced shortages, or in the time available for research to women scientists.

Fifth, several papers outline new pathways, based on positive stories of human resilience, community responses, and effective state interventions. Most prior studies have focused largely on the negative effects.

Sixth, in his editorial essay, Nobel Laureate Amartya Sen shares insights from both his personal journey and his view of science and gender from a special vantage point.

With this Special Issue we thus bring new conceptual and empirical insights on COVID-19 that, we hope, will help better understand its complex gender effects, and identify pathways for further analysis and more effective policies in the future.

We open this Special Issue with Amartya Sen's insightful editorial essay which begins by recalling how the pathbreaking research of a women scientist-Nobel Laureate Marie Curie-led to lifesaving treatment for his mouth cancer when he was just 18 years old, a story he dwells on in greater detail in his fascinating recent memoir (Sen, 2021). 'Women scientists', Sen emphasises in his editorial, 'can be leaders of gigantic departures in just the way Newton or Leibnitz or Darwin was'. This leads into his compelling essay on the relationship between gender, science and pandemics, and the inadequately recognised contributions of women scientists, and especially of women scientists of colour. The making of the important COVID vaccine, Moderna, he notes, was itself based on key contributions by African Americans, especially Kizzy Corbett, whose scientific work, along with that of Barney Graham, was at the forefront of Moderna's development.

The undercounting of female achievements, in turn, tends to discourage women from undertaking higher education and opting for 'difficult and challenging' subjects of specialization, especially (but not only) in many developing countries. Sen also points to inequalities faced by women during the pandemic which were captured by gender economists in terms of the loss of household income, lack of medical facilities, and the deprivation of resources and opportunities for child care. These gender inequalities deepen when they overlap with intersectional deprivations of race or caste.

Sen's essay is followed by twelve papers. The first of these by Bina Agarwal, as noted, outlines a conceptual framework for examining the complex effects of this pandemic and other crises. Subsequent papers then examine the gender effects of 
the pandemic on several key dimensions: health, employment, poverty, livelihoods and food security. We also bring a focused lens on the challenges faced by specific categories of women, ranging from poor widowed farmers in India on the one hand to women scientists in the Global South on the other. The final set of papers examine ways forward, drawing especially on the positive experiences of state and civil society collaboration. The papers are interdisciplinary in scope and use a range of methodologies, both quantitative and qualitative, some drawing on large secondary data sets, others on primary surveys they have themselves been involved with. Geographically, the Issue covers experiences from different parts of the Global South, including India, Peru, Brazil and China, as well as regional and global overviews.

\section{Conceptualising potential effects}

In the first paper of this Special Issue, 'Imperatives of recognising the complexities', Agarwal argues that the gendered impact of COVID-19 has both visible and hidden dimensions, and both immediate effects linked with lockdowns and longer-term effects that are likely to emerge sequentially in time. For example, livelihood loss and women's inability to recover from the economic loss suffered in the immediate onslaught of the pandemic can, in turn, lead to food and nutritional insecurity, declining savings, rising indebtedness, falling credit worthiness and deepening poverty. Over time, families may even begin to sell their assets. Past research on household coping strategies during crises suggests that these negative sequential effects tend to be borne disproportionately by women. The assets sold, for instance, are more likely to be movables, which are usually the only assets women own, rather than immovables, such as land, that mainly men own. The unfolding longer-term effects can undermine women's prospects of economic recovery as also those of their households. They can also reduce women's bargaining power vis-à-vis their spouses and senior family members, leading to worsening distributional outcomes for women.

Much of the existing feminist literature on the impact of COVID-19, Agarwal notes, has neglected these complexities and focused mainly on care work and domestic violence. This has diverted attention away from other key concerns, such as the longer-term or hidden effects mentioned above. Even care work and domestic violence have complex facets that tend to be missed. For example, time-use surveys do not capture the drudgery involved in domestic labour in the rural areas of poor countries where women have to spend long hours fetching water from outside sources due to lack of piped water in homes, or fetching firewood from local forests and commons, since firewood remains the main cooking fuel in large parts of South Asia and Sub-Saharan Africa. An increase in poverty and destitution can, in turn, lead to a rise in child marriage and even the sale of girls in desperate families, as found in examples of coping strategies under other past calamities.

Using examples from India, Agarwal outlines the kinds of gendered effects we might expect, and traces many of the effects mentioned above through existing surveys and media reports. At the same time, she points to substantial data gaps, since most of the telephonic surveys undertaken during the COVID-19 pandemic failed to 
capture these effects, not only because it is difficult to collect sensitive information by phone, but also because of an inadequate conceptualisation of possible effects in survey design. ${ }^{3}$ Hence, while the immediate morbidity and mortality effects have been reported by gender for most countries, we lack a breakdown by age, or rural/ urban areas, or other characteristics. Both surveys and media reports also missed particular indirect effects, such as on women widowed under COVID-19, given higher male mortality. Agarwal's small survey with a colleague provides interesting insights on this count. Her paper also highlights some positive stories of economic recovery, a point to which we return in Sect. 5.

In laying out the broad contours of a framework, along with tracing empirical evidence from India, Agarwal provides us a broad structure for the volume. Her particular emphasis on the limitations of existing data sets both in this Special Issue and in her other papers (Agarwal 2021 a; b), also gives leads for future research. The theme of data gaps in assessing gender differences in health outcomes of COVID-19 is carried forward further by Sarah Hawkes and her colleagues in the next paper in this Special Issue, as discussed below.

\section{Immediate impact: health and employment}

\subsection{Health}

It has long been noted that sex and gender matter in health outcomes, but in complicated ways. Although mortality rates are typically noted to be lower for women than men, not only under the onslaught of COVID-19 but also in earlier pandemics, women of reproductive ages may well suffer more due to comorbidities or a gender bias in access to health care facilities. For example, in India, during the 1918 Influenza pandemic, female excess mortality rates were much greater than for males among those in the age group 20-40 (GoI, 1920). The 1918 Report of the Sanitary Commissioner (GoI, 1920: 63) attributes this to two factors: the disease being exceptionally fatal for pregnant women, and women being caregivers in sick households while themselves being sick. Women also tended to be more undernourished than men. To capture such details for COVID-19, however, we need more than aggregate figures.

This is well brought out by Sarah Hawkes and her research team in their paper in this Special Issue. They highlight the failure of governments to provide sex-disaggregated data in health policies and programmes, especially in lower-income countries. They review the availability of national sex-disaggregated surveillance data on COVID-19 and trends on the testing-to-outcome pathway. Drawing upon 18 months of global data collection from over 200 countries, they examine if data availability varies with a country's economic status and investigate the determinants of sex differences, including the national gender inequality status of each country. They find notable gender differences in COVID-19 prevention behaviour and illness outcomes.

\footnotetext{
3 See also Agarwal (2021a; b).
} 
For instance, the uptake of vaccination and testing is lower among men, who also face a higher risk of severe disease and death.

Apart from sex and age, they argue, national data are rarely disaggregated by other inequalities such as ethnicity, geographical location, occupation or class. Where available, such intersectional data shows clear patterns of health inequity. In the United Kingdom, for example, surveillance data shows that exposure to COVID-19 varies by occupation, gender, class and ethnicity. Those from minority ethnic communities are found to be over-represented in highly exposed occupations, including health workers and care workers, most of whom are also women. However, such disaggregation in national data systems is rare. They further note that there are little data on sex-disaggregated rates of 'long-COVID', or regular reporting of indirect health impacts due to disruption to health services for non-COVIDrelated health conditions such as cancer, diabetes, mental health, and essential sexual and reproductive needs.

The authors make a strong case for 'supporting and maintaining the collection, collation, interpretation and presentation of sex-disaggregated data' which, they emphasise, requires commitment and resources at subnational, national and global levels. Not collecting such data during the pandemic, they argue, represents a major gap in our understanding of the gendered health impact of the pandemic, and is a missed opportunity for monitoring and identifying gender-responsive, evidenceinformed solutions.

\subsection{Employment}

The second most talked about effect of COVID, after morbidity and mortality, has been on the economy, and especially on jobs and livelihoods which were disrupted globally for both waged and salaried workers, as well as for the self-employment. This led to a loss of earnings across the board for most people, although varyingly by sector. Much of this discussion, however, remains ungendered. In this volume, we provide a gendered analysis in three papers which trace these effects at the national level for two countries-India and Peru.

Ashwini Deshpande points out that India is fortunate in having high frequency national-level data from the Centre for Monitoring the Indian Economy (CMIE). These data were being collected before the pandemic and continued to be collected during the pandemic via telephonic surveys. The data cover both paid work (employment) and unpaid work (time spent on domestic labour).

Deshpande analyses the effects of Covid-19 on the gender gaps in paid and unpaid work at three points in time: April 2020, August 2020, and December 2020. She uses the difference-in-differences method for estimating the situation before the pandemic set in and just after in April 2020 when India announced a strict national lockdown. She finds that April 2020 saw a large contraction in employment for both genders, but more men than women lost jobs in absolute terms. Between April and August 2020, however, male employment recovered steadily as the economy unlocked, but for women who were previously employed the likelihood of getting 
back their jobs after the lockdown was much lower than for men. By December 2020, gender gaps in employment had returned to the December 2019 levels.

On the effect of the pandemic on domestic chores, Deshpande finds that the time spent in April 2020 increased for both genders, relative to December 2019, since men picked up some of the work. However, by December 2020, the average male hours had declined to below the pre-pandemic levels, whereas women's average hours increased sharply. Notably too, the leisure time spent with friends fell more sharply for women than men between December 2019 and April 2020.

Deshpande also finds that the intersections of gender and other social identities matter. The largest decline in employment occurred for the most caste disadvantaged, namely Scheduled Caste men, followed by Scheduled Tribe men, while upper caste men registered the smallest decline. In each social group, female employment was lower than male employment, with the gender gap being least for Scheduled Tribes. By December 2020, the best recovery in terms of employment was made by upper-caste men.

Rosa Abraham, Amit Basole and Surbhi Kesar make similar observations in their paper on some counts, but extend the analysis on other counts to focus on worker characteristics. They also use CMIE's Consumer Pyramid Household Survey for India, and find that conditional on being in the workforce prior to the pandemic, women were seven times more likely to lose work during the nationwide lockdown in April 2020, and conditional on losing work, women were eleven times more likely to not return to work subsequently, compared to men, after the national lockdown ended. Interesting, too, while education shielded male workers from job loss, highly educated women were found more likely to lose their jobs.

Marriage and religion too had contrasting gender effects. For example, married women were found less likely to return to work and married men more likely to return to work. Adding religion to gender, Muslim women were found less likely to return to work, while for Muslim men religion had no significant impact. For those workers who did return to work, a large share of men in the workforce moved to self-employment or daily wage work in agriculture, trade or construction. Women, however, were constrained in terms of their ability to make alternative employment arrangements or move to other industries. The authors infer that women lack many of the 'fallback' options for employment that men enjoy, since men are more able to move across industries and employment arrangements.

Complementing these papers on India is Rosa Luz Durán's analysis for Peru. She uses quarterly data from the 2020 Peruvian National Household Survey to estimate the differentiated impacts of COVID-19 on several indicators: labour force participation, occupational categories, informality, and number of hours worked. The author evaluates the gendered impact by comparing heads of households and their spouses, and finds that the worst affected were rural women without partners but with children.

The particular vulnerabilities of rural women are also highlighted by Zhongjin Li, Ying Chen and Yang Zhan in the case of China. They note that while many urban women had some protection from economic hardship or potential health risks, through working from home during the pandemic, rural migrant women, who accounted for $35 \%$ of the entire rural migrant population of 290 million people in 
China, were especially at risk, both economically and health-wise. The same could be said for India, where, as Agarwal notes, many female migrant workers returned to their villages when lockdown was announced but were unable to return to work when the national lockdown lifted.

Unemployment is only one dimension of the economic impact of the pandemic. Neither the CMIE survey for India nor presumably the Household survey for Peru covers earnings, so a person could be employed but still earn little and fall into the ranks of the 'working poor'. Moreover, the return of international migrants has meant that households dependent on earners based abroad lose remittance income. In India, for instance, as Agarwal notes, $10 \%$ of rural households depend for over $30 \%$ of their annual household expenditure on domestic remittances from migrants, and many more depend on international remittances. These flows have been largely cut off under COVID-19 restrictions.

\section{Sequential effects: poverty and vulnerability}

For many, a loss of jobs and livelihoods is just the start. Other ill-effects can follow if households fall into poverty. It is estimated that across the Global South, 97 million were added to the ranks of the poor in 2020 (Mahler et al., 2021). How has this played out in terms of household coping strategies?

\subsection{Poverty and linked effects}

Once a household loses its major source of earnings, a whole sequence of effects can follow, as spelt out in Agarwal's paper. For example, people first draw upon savings, then borrow for consumption via informal sources such as moneylenders. If unable to repay the loan, they become less credit worthy and may begin to sell assets if joblessness continues. Households with low incomes, or those already poor or on the margins of poverty, can face nutritional deprivation and hunger.

In the initial period of the pandemic, several surveys reported growing hunger but almost none had a gendered disaggregation of food sharing within the home. In this Special Issue, however, the paper by Soumya Gupta, Payal Seth, Mathew Abraham and Prabhu Pingali provides a detailed perspective in the Indian context. They note that the stringent nationwide lockdown in India led to widespread disruptions in food access and availability, even though, technically, food value chains and allied activities were exempted from the lockdown. Using two panel datasets, they distinguish the pandemic's impact on a household's consumption of non-staples versus staples and women's dietary diversity at different levels: national, state, and district. Their detailed analysis is for four economically backward districts of three states: Uttar Pradesh, Bihar, and Odisha. All three states fall in the lower end of the spectrum in terms of per capita incomes and social indicators.

Comparing May 2020 and May 2021, they find a decline in household food expenditures and women's dietary diversity, particularly for non-staples like meats, eggs, vegetables and fruits. This occurred despite the government's outreach in 
terms of the special Public Distribution System (PDS), direct benefit transfers, and rations, which respectively reached $80 \%, 50 \%$, and $30 \%$ of the surveyed households.

As the authors note, there is in fact a growing body of evidence of women's disproportionate vulnerability to economic shocks, the impact of a grain-focused safety net programme, and restricted access to and availability of diverse nutritious foods.

\subsection{Singleness and widowhood}

Another form of vulnerability women face is from being single, especially widowed. Seema Kulkarni, Sneha Bhat, Pallavi Harshe and Swati Satpute examine the impact of COVID-19 on the livelihoods of widows and other single women farmers from the most backward districts of Maharashtra state in western India. Their paper draws on two types of evidence gathered by MAKAAM, an informal all-India women farmer's forum. Members of the Forum recorded multiple rounds of interactions with over a hundred women farmers during MAKAAM's COVID-support work under India's national lockdown in 2020, when they provided women with rations and seeds. They subsequently undertook a large-scale survey of around a thousand single women farmers, $91 \%$ of whom were widows from poor households.

The authors found that COVID-19 led to a loss of farm incomes, a decline in employment opportunities, and increased debt traps and food insecurity among the single women farmers. Pre-existing inequalities of class, caste and gender in access to food, incomes, credit, land and markets were exacerbated during the pandemic, further impoverishing the women. The paper also provides a nice illustration of sequential effects but in relation to production. For example, despite the fact that the farm sector in India was not subject to strict lockdown, women farmers faced problems in April 2020 in harvesting and selling their produce, due to labour shortages and high wages to be paid in cash. Those who were able to harvest, found it difficult to sell their crops due to lack of public transport and increased transportation costs. Some tried to sell their produce by piggybacking on the vehicles of male farmers. As one woman farmer said: 'Markets are to be accessed at the convenience of men from the village. Whenever their vehicle heads out, we have to load our produce, which has often meant delays and loss of the value of the produce'. Lower-caste women faced particular problems in making these arrangements. Most were forced to sell to local male traders at low prices. Those producing perishables, such as eggs, milk and vegetables, lost out, since local restaurants were shut and the village market was saturated with farmers wanting to sell their produce.

It was important for women to sell their output in order to get cash for repaying their loans and also investing in farm inputs for the next season's cultivation. But with reduced or no earnings, many could not repay their loans and therefore could not take on new loans. Without funds for investment, some women farmers thought they would lease out their land or leave it fallow in the next season.

Other women who were largely dependent on agricultural wage labour could not find work, since the employing farmers did not have the cash to pay the labourers. Widows and other single women are disadvantaged even in normal times in getting 
credit, inputs, labour, or a fair price for their produce. These pre-existing inequalities and exclusions by gender and caste were aggravated under the pandemic.

Women cultivators did try to support each other by sharing seed and exchanging labour. MAKAAM also tried to help them receive their food entitlements, widows' pensions, and job cards for the government's employment guarantee scheme. But, overall, the paper argues, state response was inadequate, not only in providing relief but also in partnering with women's collectives and grassroots organisations for better outcomes. Interestingly, this is in contrast to the state response in Kerala where such a partnership was a centre point of Covid response, as outlined in Ramakumar and Eapen's paper.

Widowhood is also discussed by Agarwal, but from a different angle, namely of women whose husbands had died due to COVID-19. She finds that even women who are economically comfortable face a sense of deep social isolation. They find themselves dependent on sons or other relatives to travel out, especially to visit relatives in other towns, due to social norms which restrict them from travelling alone. As one rural, upper-caste, 62-year-old, educated housewife who had been married for 46 years before she lost her spouse to COVID, said: 'What can I say about my earlier life? It was so different. I could go everywhere with my husband if I needed to... Just the absence of one man can totally overturn your life (starts crying)'. This highlights how hidden social norms can lead to unequal gender effects in a crisis. These dimensions cannot be captured by numbers.

\subsection{Past austerity}

A somewhat different perspective on poverty and vulnerability is provided by Ana Luíza Matos de Oliveira and Magali N. Alloatti, who examine the impact of Covid19 against the backdrop of austerity measures introduced by the Brazilian government prior to the pandemic. These measures, including the underfunding of social infrastructure and the abandonment of the welfare state model, the authors argue, had a disproportionately harsh effect on Brazilian women, leaving them structurally more vulnerable to the COVID-19 crisis than men.

This paper traces the effect of the pandemic by gender and race against the backdrop of prior austerity policies which deepened pre-existing structural inequalities. These included the greater dependence of women of colour on informal labour markets, the substantial burden of care work borne by women in general, and the vulnerability of single parent households which are largely female $(87.4 \%$ of single parent households in Brazil were headed by women in 2010, and their numbers have been rising).

The authors argue that the reduction of public spending had both direct and indirect effects on women. The direct effects include the progressive reduction of a fund serving low-income families largely headed by single women; cuts in a programme targeting women farmers who are also heads of their households; and budget cuts for measures aimed at combating and preventing domestic violence. The indirect gender effects emerge from the progressive defunding of a range of programmes and initiatives which were mostly benefiting women in low-income groups in terms of 
food security, nutrition, and family agriculture, and benefiting children and adolescents (especially blacks) living in extreme poverty in Brazil. The closing of schools and other social institutions (day care centres, shelters) also had a range of indirect effects. It increased women's domestic work burdens and reduced food security and the physical safety of children from low-income families for whom schools provided both. Hence, in March 2020, the rate of sexual abuse against children and adolescents rose by $85 \%$ in Brazil, compared to the same month in 2019.

Also, domestic violence increased. The paper cites research undertaken by the Brazilian Forum for Public Security, where the researchers analysed messages on social networks (twitter) between February and April 2020. They found an increase of $431 \%$ in messages reporting some kind of altercation between couples, which peaked at weekends and early morning hours. The most frequent victims were women living on minimum wages and in rural areas. Under the pandemic, given social distancing measures, women facing domestic violence could not easily seek shelter with family or friends; while, in big cities, shelters were overcrowded, with years of underspending and the failure to construct new shelters. In other words, austerity and the pandemic together created what the authors term to be an 'explosive' combination for the most vulnerable: women and children of low-income families.

\subsection{Academic challenges}

We now come to a novel paper in this volume which explores a dimension that we have not seen much explored before, namely the effect of COVID-19 on the wellbeing and intellectual achievements of women scientists, given their gender-unequal responsibilities for domestic work, childcare and eldercare, as people were forced to stay home under COVID-19. We can see this as a hidden sequential effect. It also brings us back to some of the issues relating to women scientists raised by Sen in his editorial piece.

Tonya Blowers, Erin Johnson and Jennifer Thomson surveyed some 6000+ women in STEM fields, who are members of the Organisation for Women in Science for the Developing World (OWSD), to investigate the impact of COVID-19 on the personal and professional lives of women scientists from the Global South. Of the 1465 women belonging to 80 developing countries who answered, almost $80 \%$ were primarily involved in research $(40 \%)$ or teaching $(38 \%)$.

The most common work-related problems reported by them were an inability to access their labs or offices or undertake fieldwork, reduced working hours due to housework responsibilities, and lack of reliable internet connections for effectively working from home. Even pre-pandemic, women worldwide undertook more than twice the hours of unpaid labour compared to men, and for most women this time contribution increased under the pandemic, obstructing them from reaching important professional milestones. These factors varied by region, discipline and the stage of the women's careers. For example, unreliable internet was mentioned by $54 \%$ of the respondents from Sub-Saharan Africa, but only by $20 \%$ of those from Latin 
America and the Caribbean. All these factors would have affected their research output as well. ${ }^{4}$

Notably, though, the paper argues, the lives of women scientists rarely follow the ideal 'pipeline' metaphor of entering universities at one end and moving steadily through a competitive system until they emerge as respected scientists at the other end. Rather, they 'meander', taking detours to serve the needs of communities and families: in other words, they follow a path based more on inclusiveness and cooperation. This is also captured in their responses to the pandemic. While being negatively affected professionally due to extended housework and childcare, some $83 \%$ said they also valued spending more time with their families, especially their children.

\section{Ways forward}

As we look back to find ways forward, we note that, on the one hand, people tried to cope with the fallouts from the pandemic the best they could, supported in varying degrees by government relief measures. On the other hand, we also have encouraging positive stories of communities and civil society organisations which assisted those in need, with particularly good outcomes where civil society and the state were able to join hands in a symbiotic way.

Awino Okech, Shereen Essof and Laura Carlsen discuss the work of Just Associates (JASS), a feminist support organisation that strengthens the leadership and organising capacity of community-based women's networks in Southern Africa, Southeast Asia, and Mesoamerica. JASS runs a mobilisation fund (JMF) established in 2019 as a crisis response fund to provide small-scale, immediate support for feminist groups organising responses to food security, health, rights and safety for all. Although JASS is not a funder, its vision of providing agile, micro-level financial support in crisis can be very effective. Through a combination of local networks, and formal and informal remittances, JASS gets money to women's groups speedily under crisis, when larger donors may be unable to do so, or be too late.

Under COVID-19, JASS drew on this long history of supporting women's organising during the HIV/AIDS epidemic to support feminist groups responding to COVID-19. Between April 1 and December 30, 2020, JMF disbursed almost US\$175,000 to groups in Mesoamerica, Southeast Asia and the Southern Africa. Four months after disbursing the money, JASS conducted surveys during August-September 2020 of JMF recipients with 37 partners, to find out how the funds were used. Depending on region, they found that the funds had variously

\footnotetext{
${ }^{4}$ In fact, a recent study by Squazzoni et al. (2021) looked at submitted manuscripts and peer review activities for all Elsevier journals between February and May 2018-2020, including data on over 5 million authors and referees. It found that while overall submissions surged during the first wave of the pandemic, women submitted proportionally fewer manuscripts than men. The pattern was similar across all the research fields examined, from engineering to economics. Women at the early stages of their careers (who were most likely to have young children) were the most disadvantaged. This could also have a negative effect on their future careers.
} 
helped curb the spread of COVID-19 in informal settlements, supported women's income-generating activities, established a safety committee that opened a soup kitchen for impoverished families, and helped locate and evacuate survivors of domestic violence.

These are impressive results. However, in terms of scale and reach, COVID support appears to have been especially effective where the state and communities were able to work together, as in the case of Kerala in India and China more generally.

R. Ramakumar and Mridul Eapen discuss why the state of Kerala in south India stood out in its pandemic response. Kerala's response effectively attended to both the health aspect of the pandemic and the economic aspect, through close cooperation between the state and civil society, and the institutions built in the pre-pandemic period.

In terms of health effects, for instance, Kerala has had the lowest case morality rate of all states in India. Kerala's success in preventing avoidable deaths, despite high infections, the authors argue, was largely the result of meticulous communitycentred mobilisation which helped contain, track and monitor the health crisis. Women participated in large numbers in health administration, not only as nurses but also as the 'silent, often faceless', essential workers, ASHA (Accredited Social Health Activists) and anganwadi workers. ${ }^{5}$ They were joined by some 325,000 voluntary youth brigade members, of whom about a quarter were young women. This was bolstered by state-wide campaigns to 'Break the Chain' in 2020 and 'Crush the Curve' in 2021.

The paper also describes the major role played by women attached to the state's poverty eradication mission, Kudumbashree, which was launched in 1998. It educated 2.2 million neighbourhood savings-and-credit groups about social distancing and sanitisation, and created Whatsapp groups. Kudumbashree workers were also trained to care for COVID-positive patients, particularly the destitute and those with disabilities in their own villages. And when the vaccination drive began in January 2021, Kudumbashree workers helped households register, so that no household was left out. Their familiarity with the local population and effective training greatly increased state capacity.

In economic terms, while people in Kerala too, like in other states, suffered a loss of jobs and livelihoods, the state government provided a social safety net through a range of measures, such as encouraging Kudumbashree's microenterprises to produce and sell masks and hand sanitisers; providing cash transfers to households- $61 \%$ of the roughly 5 million beneficiaries were women, almost all from economically disadvantaged groups; and boosting rural employment by expanding and effectively implementing the national MGNREGS (Mahatma Gandhi Rural Employment Guarantee Scheme) which guarantees one person per every rural household a 100 days of employment annually, in unskilled manual

\footnotetext{
5 Anganwadis are rural child care centres begun in 1975 by the Government of India as part of the Integrated Child Development Services programme, to combat child hunger and malnutrition. A typical Anganwadi center also provides basic health care in a village and is part of the Indian public health care system.
} 
work. Boosting this programme in the pandemic greatly increased the number of person-days generated, about 90 per cent of which were female person-days, exceeding corresponding figures for the pre-pandemic period in 2019-2020. In addition, community kitchens were started throughout the state through the Kudumbashree Mission, thus ensuring that no one went hungry during the 2020 lockdown. Although many other states also provided support of various kinds, their measures were less effectively implemented.

The authors argue that Kerala's success was due to its historical preparedness and contemporary policy innovations. These measures were built on pre-pandemic links between the state and civil society, which helped meet the challenges of a disaster such as the pandemic. In the 1990s, when India sought to limit state intervention and promote market-based solutions, Kerala focused on community participation and empowering women. Hence, although like other Indian States, in Kerala too the pandemic led to a reduction in female employment, a rise in gender-based violence and women's work burdens, and a deterioration in women's mental health, Kerala's response was distinctive. The economic relief package included cash support, employment, free food provisioning and zero-interest loans to women. Through helplines, the government also helped women report violence and mental stress.

Agarwal highlights another aspect of Kerala's success story which complements that of Ramakumar and Eapan, namely the economic survival of women's group farms: Kerala has some 68,000 such farms where poor women lease in land in small groups and pool their labour and capital to farm collectively. In March 2020, some 30,000 such group farms were cultivating, of which $87 \%$ survived economically as they were able to harvest their crops through group labour and sell much of their produce to the community kitchens being run by Kudumbashree. In contrast most individual family farms, largely male-managed, lost out.

The gender-sensitivity of Kerala's pandemic response is a rich demonstration of the possibility of state-community collaboration, and of the need to build such responsiveness into the system to deal with serious crises.

Strikingly, this is a lesson derived also from a very different context and political system from India's, namely that of China. In their paper, Li et al. describe how community-centered social infrastructure (an assemblage of state, family, and local resources), was key to the country's pandemic response, in combating the virus and providing essential services to people.

The authors argue that unlike many countries where civil society networks are independent of the state, in China, community organisations are the neighbourhoodbased governing units in urban areas and villages in rural areas. They are financially sponsored and organisationally supported by the state. The authors cite studies which found that over $70 \%$ of people nationwide received direct service or help from community workers, when they encountered difficulties during the 2020 lockdown. For instance, in the city of Wuhan, the epicentre of the crisis that experienced the earliest and the strictest lockdown, 79\% of residents reported receiving direct help from community workers, even higher than the $76 \%$ who reported support from families and friends. Nationwide, roughly half of the people surveyed in another study received direct help from community workers which they deemed to be very important in the pandemic. 
The community-level organisations provided a range of support services: delivering basic necessities to families when people's mobility was restricted; delivering food and medicine to every household in the neighbourhood so that the unnecessary movement of people could be reduced; and disseminating virus-control tips. The organisations also coordinated essential health services, including screening and contact tracing and taking people to diagnostic centres. In addition, they coordinated residents who volunteered to help with contact tracing and health monitoring daily.

The level of performance of the community-level organisations, however, varied across regions in China. They did especially well in neighbourhoods which were more cohesive, shared a strong sense of solidarity, and participated actively in neighbourhood businesses. In 'mixed residential communities', where housing was more commercialised and the residents were a diverse body with loose internal connections, these community organisations were less effective. Overall, however, the authors stress the crucial importance of state-community collaboration for effective responses and also for ensuring some degree of equity between the well-off and poorer regions of China.

\section{Concluding reflections}

The term "long COVID" has been used to highlight the lingering negative effects on the health of those who have had COVID. This term can also be used creatively to describe the pandemic's long-term economic consequences. Framing it in this way helps us highlight at least four features as we look ahead.

First, it calls attention to the sequential fall-outs for the women and men who lost their livelihoods and did not recover, hitting a spiral of depleting savings, assets, and indebtedness; in other words, those who slid below the threshold of resilience, and the gender differentials therein.

Second, it points to the imperatives of continued monitoring of both the health and the economic outcomes, through systematic gender-disaggregated data collection. To the extent possible, these data should be both in terms of longitudinal panels and one-time intensive surveys of vulnerable populations, such as single women households, low-income rural households, and so on.

Third, we can learn much from re-examining how people have coped with other pandemics as well as other severe economic crises. The conceptual framework highlighted in this Special Issue drew especially from the coping strategies of poor households in the countries of South Asia, and the unequal gendered burdens in that coping which often remain hidden, as women typically sacrifice more. Studying contextualised past behaviour (which can vary regionally and culturally) can help us anticipate what may emerge in future pandemics and how to plan for reducing the costs. It would also help us design our surveys more sensitively, to capture the hidden and indirect impact on women, especially those poor and socially disadvantaged.

Fourth, the better we are able to reveal the longer-term effects, the more effective can be our policy responses to build in resilience. Some of the papers in fact make specific policy recommendations. Gupta et al. emphasise the need for 
diversification in the Indian government's Public Distribution System to include nutrition-rich foods, and the importance of direct benefit transfers to women to help them overcome intra-household nutritional disadvantages. Kulkarni et al. make a case for strengthening social security measures for single women farmers and enhancing their access to productive resources and agricultural programmes. Agarwal emphasises a group approach to livelihood enhancement for women, and for empowering women for better accessing productive assets.

Fifth, we have seen from our discussion that crises preparedness is best where the framework for social protection pre-exists, rather than being hastily pulled together after the crisis has hit us. The JASS response had emerged in previous crises, while both in Kerala (India) and China the civil society networks were linked to the state as part of the framework for development. In Kerala, this was specifically imagined and designed as (what Agarwal terms) a 'women-centric' model of development, which focused on women as the central agents of change and promoted cooperation in groups. Agarwal, Ramakumar and Eapen, as well as Li et al., all highlight the potential of groups and communities in enhancing women's economic recovery and providing social protection from the worst outcomes of the pandemic. This approach could guide us towards more effective policy pathways for 'building back better.'

To conclude, in outlining developmental frameworks and policies, the role of women scientists is likely to prove critical-be they specialists in the natural sciences, economics, other social sciences, institutional design, Planning, or other important specialisations. And, as Amartya Sen argues in his editorial, their work warrants widespread recognition.

Acknowledgements We warmly thank Professor Alberto Quadrio Curzio, editor-in-chief of Economia Politica, for inviting us to co-edit this Special Issue. His enthusiasm for the Issue, many helpful suggestions, and generous praise for our efforts as we progressed, also energized us through COVIDfatigue. In addition, we thank our authors for their fine pieces, as well as our peer-reviewers for their valuable time and useful comments.

\section{References}

Agarwal, B. (2021a). Livelihoods in COVID times: Gendered perils and new pathways in India. World Development. https://doi.org/10.1016/j.worlddev.2020.105312

Agarwal, B. (2021b). Reflections on the less visible and less measured: Gender and COVID-19 in India. Gender and Society, 35(2), 244-255.

Feminist Economics. (2021). A special issue on feminist economic perspectives on the COVID-19 pandemic. Feminist Economics. https://doi.org/10.1080/13545701.2021.1876906

Feminist Studies. (2020). Feminist analysis of Covid-19. Feminist Studies, 46(3) (journal special issue).

Gender and Society. (2021). Special issue on Covid and gender. Gender \& Society, 35(2). https://journ als.sagepub.com/toc/gas/35/2

Government of India. (1920). Annual Report of the Sanitary Commissioner for the Government of India for 1918, Calcutta.

Mahler, D. G., Yonzan, N., Lakner, C., Aguilar, A. C., \& Wu, H. (2021). Updated estimates of the impact of COVID-19 on global poverty: Turning the corner on the pandemic in 2021? World 
Bank blogs, June 24. https://blogs.worldbank.org/opendata/updated-estimates-impact-covid-19global-poverty-turning-corner-pandemic-2021

Sen, A. K. (2021). Home in the world: A memoir, Allen Lane.

Squazzoni, F., Bravo, G., Grimaldo, F., García-Costa, D., Farjam, M., \& Mehmani, B. (2021). Gender gap in journal submissions and peer review during the first wave of the COVID-19 pandemic. A study on 2329 Elsevier journals. PLOS ONE. https://doi.org/10.1371/journal.pone.0257919

Publisher's Note Springer Nature remains neutral with regard to jurisdictional claims in published maps and institutional affiliations. 